\title{
Development of Small-Diameter Elastin-Silk Fibroin Vascular Grafts
}

\author{
Takashi Tanaka ${ }^{1}$, Yasuyuki Abe $^{2}$, Chieh-Jen Cheng ${ }^{3}$, Ryo Tanaka ${ }^{1}$, Akira Naito $^{2}$ and \\ Tetsuo Asakura ${ }^{2 *}$ \\ ${ }^{1}$ Department of Veterinary Surgery, Tokyo University of Agriculture \& Technology, Fuchu, Japan, ${ }^{2}$ Department of \\ Biotechnology, Tokyo University of Agriculture \& Technology, Koganei, Japan, ${ }^{3}$ Department of Veterinary Medicine, College of \\ Bioresource Sciences, Nihon University, Fujisawa, Japan
}

\section{OPEN ACCESS}

Edited by:

Chengchen Guo,

Westlake University, China

Reviewed by:

Mingzhong Li,

Soochow University, China

Feng Wang,

Southwest University, China

*Correspondence:

Tetsuo Asakura

asakura@cc.tuat.ac.jp

Specialty section:

This article was submitted to

Biomaterials,

a section of the journa

Frontiers in Bioengineering and

Biotechnology

Received: 28 October 2020

Accepted: 15 December 2020

Published: 14 January 2021

Citation:

Tanaka T, Abe Y, Cheng C-J, Tanaka R, Naito $A$ and Asakura $T$

(2021) Development of Small-Diameter Elastin-Silk Fibroin Vascular Grafts.

Front. Bioeng. Biotechnol. 8:622220. doi: $10.3389 /$ fbioe. 2020.622220
Globally, increasing mortality from cardiovascular disease has become a problem in recent years. Vascular replacement has been used as a treatment for these diseases, but with blood vessels $<6 \mathrm{~mm}$ in diameter, existing vascular grafts made of synthetic polymers can be occluded by thrombus formation or intimal hyperplasia. Therefore, the development of new artificial vascular grafts is desirable. In this study, we developed an elastin (EL)-silk fibroin (SF) double-raschel knitted vascular graft $1.5 \mathrm{~mm}$ in diameter. Water-soluble EL was prepared from insoluble EL by hydrolysis with oxalic acid. Compared to SF, EL was less likely to adhere to platelets, while vascular endothelial cells were three times more likely to adhere. SF artificial blood vessels densely packed with porous EL were fabricated, and these prevented the leakage of blood from the graft during implantation, while the migration of cells after implantation was promoted. Several kinds of ${ }^{13} \mathrm{C}$ solid-state NMR spectra were observed with the EL-SF grafts in dry and hydrated states. It was noted that the EL molecules in the graft had very high mobility in the hydrated state. The EL-SF grafts were implanted into the abdominal aorta of rats to evaluate their patency and remodeling ability. No adverse reactions, such as bleeding at the time of implantation or disconnection of the sutured ends, were observed in the implanted grafts, and all were patent at the time of extraction. In addition, vascular endothelial cells were present on the graft's luminal surface 2 weeks after implantation. Therefore, we conclude that EL-SF artificial vascular grafts may be useful where small-diameter grafts are required.

Keywords: silk fibroin, elastin, vascular graft with small diameter, ${ }^{13} \mathrm{C}$ solid-state NMR, biomaterials

\section{INTRODUCTION}

Atherosclerosis and heart disease caused by dietary and lifestyle changes account for a significant proportion of morbidity and mortality worldwide. Vascular replacement surgery is a common procedure for such vascular diseases, and bypass surgery for revascularization is in great demand for such patients (Kibbe et al., 2010). Although vascular grafts with more than a $6 \mathrm{~mm}$ diameter, made of synthetic polymers, have a high patency rate (Budd et al., 1991; Takagi et al., 2010), these materials are not suitable for small-diameter $(<6 \mathrm{~mm})$ vascular replacement because of poor patency and occlusion. Therefore, other blood vessels, such as the internal thoracic artery, radial artery, and saphenous vein, are used for small-diameter vascular procedures (Yokota et al., 2008). Autologous vascular grafts are 
limited in length and diameter. Furthermore, patients who need vascular surgery often have diabetes and arteriosclerosis, and the candidate blood vessels for grafts may be impaired and cannot be harvested in many cases. Urgent operations may be impractical due to the time required to obtain the vascular grafts. Therefore, there is a need to develop a small-diameter artificial vascular graft that is easy to handle.

Silk fibroin (SF) is a natural protein produced by the silkworm and is well-known as an excellent textile material (Asakura et al., 2018). The SF fibers possess excellent mechanical properties owing to a combination of high tensile strength and breaking strain (Fu et al., 2009; Koh et al., 2015; Asakura et al., 2018). Over the past decades, significant experimental and theoretical efforts have been made to understand the relationship between the structure and the properties of the SF fibers, with some success (Fu et al., 2009; Koh et al., 2015; Pereira et al., 2015; Asakura et al., 2020a,b). This protein also has high biocompatibility, controllable biodegradability, and low toxicity. Therefore, it has also been used as a suture material for more than 2,000 years (Altman et al., 2003; Vepari and Kaplan, 2007; Thurber et al., 2015; Tamara et al., 2018; Holland et al., 2019). SF has been recently tried as a suitable candidate for vascular grafts $<6 \mathrm{~mm}$ in diameter, as reviewed by Thurber et al. (2015), Wang et al. (2017), and by us (Asakura et al., 2019). SF vascular grafts are stiff and lacking in elasticity and need to be modified for better performance when transplanted in animals.

Elastin (EL) is an important component of the extracellular matrix of vessels. It provides elasticity in arteries, lungs, and skin (Mitchell and Niklason, 2003; Wise et al., 2009; Muiznieks et al., 2010; Baldock et al., 2011; Wang et al., 2019). In addition, EL facilitates biological functionality, i.e., minimizing platelet adhesion and reducing thrombus formation, promoting endothelial migration for angiogenesis, and regulating smooth muscle cell phenotype and proliferation (Waterhouse et al., 2011; Wang et al., 2019). Thus, EL is a very strong candidate for compensating for the shortcomings of SF blood vessel grafts. However, because of its highly crosslinked nature, EL is insoluble and difficult to use as a biomaterial (Nivison-Smith et al., 2010). Partridge et al. (1964) and Miyamoto et al. (2009) prepared watersoluble EL from insoluble EL by hydrolysis with oxalic acid. The soluble EL retains the elastic and biological properties of native EL (Miyamoto et al., 2009).

In this study, the water-soluble EL, as prepared by Miyamoto et al., was shown to improve cell adhesion and demonstrated anti-thrombogenic properties compared with SF in in vitro experiments. Then, a $1.5 \mathrm{~mm}$ diameter EL-SF artificial vascular graft was prepared by fabrication of a double-raschel knitted SF vascular graft (Yagi et al., 2011; Aytemiz et al., 2013; Fukayama et al., 2015a,b; Tanaka et al., 2018, 2020) densely packed with porous EL. The coacervation of EL, characterized by an inverse temperature transition (Wang et al., 2019), is an important prerequisite for crosslinking in preparing the EL-SF graft. The improvements in adhesion and anti-thrombogenic properties of EL were compared with SF. A comparison of the physical properties of SF-coated and EL-SF grafts was also made. Additionally, EL-SF grafts in the dry and hydrated states were studied at the molecular level using a combination of ${ }^{13} \mathrm{C}$ refocused insensitive nuclei enhanced by polarization transfer $\left({ }^{13} \mathrm{C}\right.$ r-INEPT), ${ }^{13} \mathrm{C}$ cross-polarization/magic angle spinning $\left({ }^{13} \mathrm{C} \mathrm{CP} / \mathrm{MAS}\right) \mathrm{NMR}$, and ${ }^{13} \mathrm{C}$ dipolar decoupled-magic angle spinning $\left({ }^{13} \mathrm{C}\right.$ DD/MAS) NMR (Nishimura et al., 2018; Tanaka et al., 2018). The ${ }^{13} \mathrm{C} \mathrm{r}$ - INEPT where the pulse sequence was developed for solution, NMR selectively observes the mobile components of the EL-SF graft in the hydrated state with fast isotropic motion $\left(>10^{5} \mathrm{~Hz}\right.$ ) (Saitô et al., 2002). In contrast, ${ }^{13} \mathrm{C}$ CP/MAS NMR selectively observes the immobile components of the samples or those with very slow motion $\left(<10^{4} \mathrm{~Hz}\right)$ in the dry and hydrated states (Saitô et al., 2002). If the penetration of water molecules causes a local increase in the chain mobility of the graft, a loss in the CP signals occurs, and such a mobile domain cannot be observed in the ${ }^{13} \mathrm{C} \mathrm{CP} / \mathrm{MAS}$ NMR spectra (Yang et al., 2000; Kishore et al., 2002; Holland et al., 2008). In addition, ${ }^{13} \mathrm{C}$ DD/MAS NMR can be used to obtain structural information on both the mobile and immobile domains of the silk proteins in the hydrated state. Finally, the EL-SF grafts were implanted into the abdominal aorta of rats, and removed at 2 , 4 , and 12 weeks after implantation to evaluate their patency and remodeling ability. Based on these results, we showed that the EL-SF grafts prepared here are suitable for use as small-diameter $(<6 \mathrm{~mm})$ vascular grafts.

\section{MATERIALS AND METHODS EL and SF}

For this study, we used water-soluble EL (EL-A; molecular weight 25,200 , elastic modulus $>50 \mathrm{kPa}$ and aggregation temperature 20-22. $6^{\circ} \mathrm{C}$ ) (extracellular matrix laboratories, Mie, Japan). The soluble EL-A sample was prepared by fractionation based on the elastic modulus and aggregation temperature of soluble EL, prepared from the insoluble EL of porcine aortas, by treatment with $0.25 \mathrm{M}$ oxalic acid (Miyamoto et al., 2009). Hereafter, we refer to the water-soluble EL-A as EL in this paper.

The aqueous solution of SF was prepared as described in our previous papers (Asakura et al., 1984; Yagi et al., 2011; Saotome et al., 2015; Tanaka et al., 2018, 2020). Briefly, SF fibers obtained from cocoons were degummed in a mixture of sodium carbonate $(8 \%, \mathrm{w} / \mathrm{v})$ and Marseille soap $(12 \%, \mathrm{w} / \mathrm{v})$ at $95^{\circ} \mathrm{C}$ for $120 \mathrm{~min}$ to completely remove the silk sericin (SS). They were dissolved by adding $\mathrm{CaCl}_{2}-\mathrm{H}_{2} \mathrm{O}-\mathrm{EtOH}$ solution (molar ratio: 1:8:2) to the SF at a concentration of $10 \%(\mathrm{w} / \mathrm{v})$ and then boiling at $70^{\circ} \mathrm{C}$ for $1 \mathrm{~h}$. The solution was then filtered to remove residual solid components and dialyzed with a cellulose dialysis membrane against distilled water at $4^{\circ} \mathrm{C}$ for 3 days to produce the aqueous solution of SF.

\section{Cell Adhesion Experiment}

Human umbilical vein endothelial cells (HUVECs, Lonza, Inc., Switzerland) were used for the cell adhesion experiment with SF and EL- coated 24-well plates (Saotome et al., 2015). To prepare these, after EL was spread on the plates, $10 \%$ glutaraldehyde was added to crosslink the EL (Dardik et al., 2002; Osborne et al., 2008). After removing the glutaraldehyde, the surface was washed with $70 \%$ ethanol and then three times with phosphatebuffered saline (PBS). The HUVECs, cultured in endothelial basal 
medium-2 (EBM-2, Lonza, Inc. Switzerland), were incubated at $37^{\circ} \mathrm{C}$ for 1 day. The cultured HUVECs were washed with PBS, detached with $0.25 \%$ trypsin, washed, and resuspended in the medium. The HUVEC suspension was added to SF and ELcoated 24-well plates at a concentration of $2 \times 10^{5}$ cells/well. The cells were cultured at $37^{\circ} \mathrm{C}$ and $5 \% \mathrm{CO}_{2}$ for $5 \mathrm{~h}$. After removing the supernatant, the living cells were stained with Calcein AM (Takara Bio Inc., Japan). The number of cells was counted using a fluorescence microscope BIOREVO BZ9000 with BZ-H1C software (Keyence Co., Ltd., Japan). Three points were selected on each plate, and the number of cells was determined and averaged. The cultivations were performed three times with HUVEC.

\section{Platelet Adhesion Experiment}

Dog blood in a collection tube containing citric acid was centrifuged for $15 \mathrm{~min}$ at $3,000 \mathrm{rpm}$. The supernatant was collected to obtain the canine platelet-rich plasma (PRP). The PRP on EL and SF- coated 24-well plates was incubated at $37^{\circ} \mathrm{C}$ for $3 \mathrm{~h}$. After light cleaning with PBS, the EL was fixed with glutaraldehyde for $1 \mathrm{~h}$ at room temperature. After washing with PBS and drying, the number of platelets at three points was counted on the images with a scanning electron microscope (SEM) (VE-7800; Keyence Co., Japan) and averaged. The experiments were performed three times with PRP.

\section{Preparation of EL-SF Grafts}

The $1.5 \mathrm{~mm}$ diameter double-raschel knitted silk tubes with high elongation and contraction properties were prepared with silk fibers containing reduced SS. We used a computer-controlled double-raschel knitting machine (Fukui Wrap Knitting Co., Ltd.) (Tanaka et al., 2018, 2020). Textured wefts were passed through the loops of Denbigh-stitched warps to form a structure, with the wefts as the female member of the hook-and-loop fastener. The SS in the knit tube was then removed completely by degumming as described previously (Yagi et al., 2011; Aytemiz et al., 2013).

Next, a $1.5 \mathrm{~mm}$ diameter PTFE rod was inserted into the SF knitted tube and immersed in a test tube filled with EL aqueous solution at $10^{\circ} \mathrm{C}$ for $1 \mathrm{~h}$. After incubation at $50^{\circ} \mathrm{C}$ for $30 \mathrm{~min}$ to coacervate the EL, the SF knitted tube containing EL was transferred to a test tube containing the $5 \mathrm{w} / \mathrm{v} \%$ glutaraldehyde aqueous solution. It was immersed for $5 \mathrm{~min}$ then, using $70 \%$ ethanol, it was washed and immersed overnight for sterilization. The graft was removed from the PTFE rod to be used for the next experiments. The preparation of the SF-coated SF graft used for comparison has been described (Yagi et al., 2011; Aytemiz et al., 2013; Fukayama et al., 2015a,b; Tanaka et al., 2018, 2020). The inner and outer surfaces of the SF graft and EL-SF graft were examined with the SEM. Hematoxylin and eosin (HE) staining was performed to examine the inner part of the EL-SF graft structure.

\section{Physical Properties of EL-SF Grafts}

The circumferential tensile strengths of the SF graft, SF-coated SF graft, and EL-SF graft were determined using an EZ-graph manufactured by SIMAZU, Kyoto, Japan (Saotome et al., 2015). The road cell was $100 \mathrm{~N}$, and the rate of stretching was $2 \mathrm{~mm} / \mathrm{min}$.
Moreover, the circumferential compressive elastic modulus of the knitted grafts was also determined using the EZ-graph. However, we could not measure the compressive elastic modulus of the SF graft because it collapsed immediately. The road cell was $5 \mathrm{~N}$, and the rate of compression was $2 \mathrm{~mm} / \mathrm{min}$. The elastic modulus $\left(\mathrm{N} / \mathrm{mm}^{2}\right)$, when compressed to $25 \%$ of the diameter, was calculated using the analysis software TRAPEZIUM. Ten dry, short, ring-shaped specimens with an axial length of $10 \mathrm{~mm}$ were prepared for the determinations, conducting four parallel tests, and the values were averaged.

\section{Characterization of Dry and Hydrated EL-SF Grafts With ${ }^{13} \mathrm{C}$ Solid-State NMR}

The ${ }^{13} \mathrm{C}$ CP/MAS, ${ }^{13} \mathrm{C}$ DD/MAS, and ${ }^{13} \mathrm{C}$ r- INEPT NMR spectra of the EL-SF grafts in the hydrated state and the ${ }^{13} \mathrm{C} \mathrm{CP} / \mathrm{MAS}$ NMR spectrum of the grafts in the dry state were observed with a Brucker Avance 400 NMR spectrometer. After hydration overnight, the EL-SF was carefully inserted into a zirconia rotor and sealed with a PTFE insert to prevent dehydration during the NMR observations (Asakura et al., 2015a). Typical experimental parameters for the ${ }^{13} \mathrm{C} \mathrm{CP} / \mathrm{MAS}$ NMR experiments were as follows. A $4 \mathrm{~mm}$ double resonance MAS probe, a MAS frequency of $8.5 \mathrm{kHz}, 3.5 \mu \mathrm{s}{ }^{1} \mathrm{H} 90^{\circ}$ pulse, $1 \mathrm{~ms}$ ramped $\mathrm{CP}$ pulse with $71.4 \mathrm{kHz}$ rf field strength, two-pulse phase modulation (TPPM) ${ }^{1} \mathrm{H}$ decoupling during acquisition, 2,176 data points, $8 \mathrm{k}$ scans, and $4 \mathrm{~s}$ recycle delay at room temperature. Details of the NMR experimental conditions for the ${ }^{13} \mathrm{C}$ DD/MAS NMR experiments have been described earlier (Asakura et al., 2015a). Typical experimental parameters for the refocused INEPT NMR experiments included a $3.5-\mu \mathrm{s}{ }^{1} \mathrm{H}$ and a $3.6-\mu \mathrm{s}{ }^{13} \mathrm{C} 90^{\circ}$ pulse, an inter-pulse delay of ${ }^{1} \mathrm{~J}_{\mathrm{CH}} / 4\left({ }^{1} \mathrm{~J}_{\mathrm{CH}}=145 \mathrm{~Hz}\right)$, a refocusing delay of ${ }^{1} \mathrm{~J}_{\mathrm{CH}} / 6$ or ${ }^{1} \mathrm{~J}_{\mathrm{CH}} / 3$. The ${ }^{13} \mathrm{C}$ chemical shifts were calibrated externally through the methylene peak of adamantane observed at $28.8 \mathrm{ppm}$ with respect to external tetramethylsilane (TMS) at 0 ppm (Asakura et al., 1984).

\section{In vivo Evaluation of EL-SF Grafts by Implantation in a Rat}

All experimental procedures and protocols were approved by the Tokyo University of Agriculture and Technology (TUAT, Approval number: 27-100). The rats were managed and cared for in accordance with the standards established by TUAT and described in its "Guide for the Care and Use of Laboratory Animals. EL-SF grafts were implanted in the abdominal aorta of 12 rats under a stereoscope (LEICA M60; Leica Microsystems GmbH-Wetzlar, Germany) (Fukayama et al., 2015a,b; Tanaka et al., 2018, 2020). Three of the rats were sacrificed at 2 weeks after implantation, six at 4 weeks, and the remaining three, at 12 weeks. The EL-coated SF grafts were $1 \mathrm{~cm}$ in length and $1.5 \mathrm{~mm}$ in inner diameter. The rats were anesthetized with intraperitoneal pentobarbital (50 $\mathrm{mg} / \mathrm{kg}$ of body weight). The abdominal aorta was carefully exposed, and the aortic branches in this segment were ligated. The aorta was removed and replaced with an EL-SF graft by an end-to-end anastomosis using 90 monofilament nylon sutures (BEAR, Japan). The distal and, subsequently, the proximal vascular clamps were slowly removed, 
A
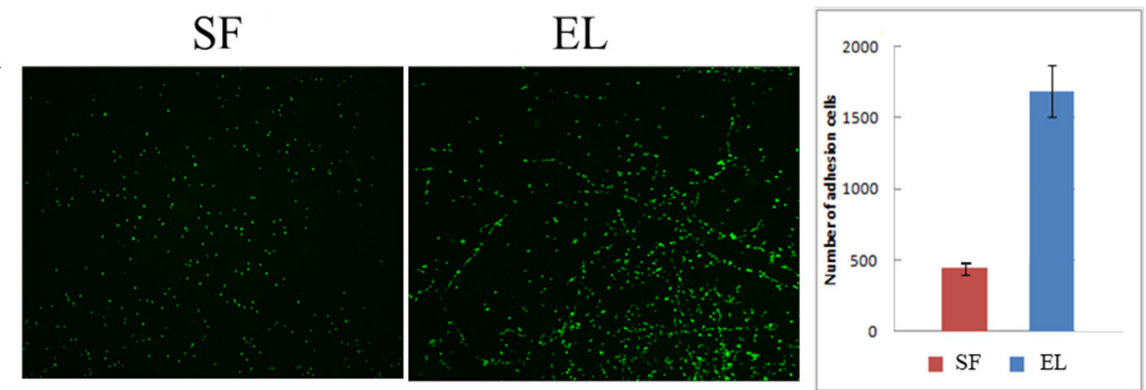

B
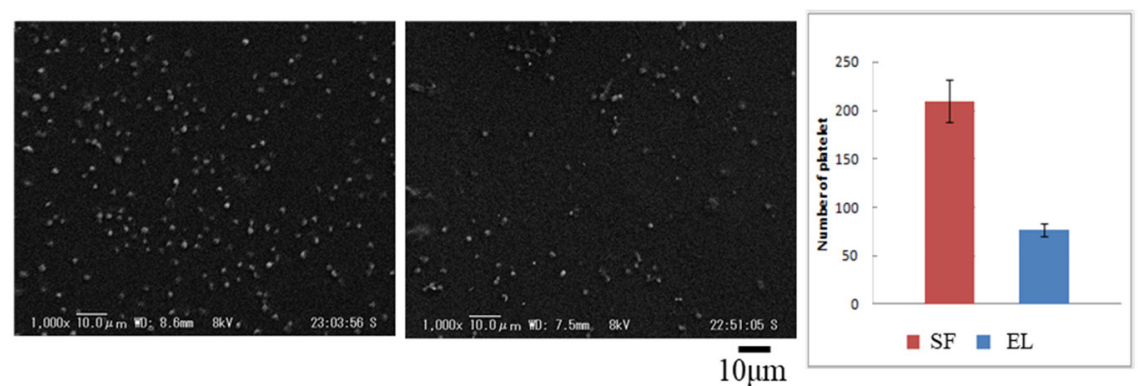

$10 \mu \mathrm{m}$

FIGURE 1 | (A) (left) Pictures of attachment of human umbilical vein endothelial cells on silk fibroin (SF) and elastin (EL)-coated 24-well plates. (right) The number of cell attachments shown as a histogram. (B) (left) Scanning electron microscope images of platelet adhesion on SF and EL-coated 24-well plates (right). The number of platelet attachments shown as a histogram.

and flow was restored through the grafts. Graft patency was confirmed visually. No anticoagulant or antiplatelet agents were administered postoperatively. Before euthanasia, the rats were perfused with $0.9 \%$ saline solution through the left ventricle. The grafts were carefully removed together with the surrounding tissue, and a $4 \mathrm{~mm}$ transverse cut at the center was made. The sutured parts of the remaining native blood vessel and artificial vascular graft were cut transversely. These samples were fixed with ethanol for histological analysis. Fixed samples were embedded in paraffin and stained with HE, Masson's trichrome (MTC). Sections for immunohistochemical staining were incubated with primary antibodies, including CD31 antirat antibody (BD biosciences Inc. San Jose, CA, USA). These samples were incubated with N-Histofine Simple Stain Rat MAXPO (Nichirei Biosciences Inc. Tokyo, JAPAN). Subsequently, color development was performed using the ImmPACT DAB Peroxidase Substrate Kit (Vector Laboratories Inc. Burlingame, CA, USA).

\section{RESULTS}

\section{Cell and Platelet Adhesion Experiments With SF and EL}

Figure 1 (A: left) shows the pictures of HUVEC attachment to SF and EL-coated 24-well plates. The number of HUVECs was greater for the EL-coated plate than for the SF-coated plate, 1684 \pm 180 , and $449 \pm 54$, respectively, Figure 1 (A: right). Thus, EL exhibited a three-fold higher attachment rate of HUBECs. Figure 1 (B: left) shows SEM images of platelet adhesion on SF and EL-coated 24-well plates. The attachment rate of platelets was three-fold higher for SF, compared to EL, Figure 1 (B: right). The platelet adhesion count for EL and SF-coated 24-well plates was $76 \pm 6$ and $210 \pm 22$, respectively. In summary, EL had a higher attachment rate for HUVECs and a lower attachment rate for platelets than SF. Therefore, EL has promising anti-thrombosis properties that may be beneficial for future applications of smalldiameter grafts.

\section{SEM and Microscope Observations of EL-SF Grafts}

The SEM images are shown in Figure 2A double-raschel knitted SF graft before coated by EL. The graft prepared by the doubleraschel knitting machine is very porous. Low-molecular-weight materials can easily diffuse out, and therefore too much blood would leak without a proper coating on the graft. The inner and outer surfaces of the SF graft appear to be properly coated by EL, as shown in Figure 2B. As shown in Figure 3, the HE staining of the EL-SF graft shows that the gaps between the SF fibers in the double-raschel knitted graft were filled with spongy EL. Thus, it is expected that the leakage of blood would be effectively prevented, and the infiltration of cellular tissue into the graft would be promoted.

\section{Physical Properties of SF- and EL- SF Grafts}

A further examination of the EL-SF grafts was performed by determining the physical properties and characterization by several kinds of ${ }^{13} \mathrm{C}$ solid-state $\mathrm{NMR}$ at the molecular level. Figure 4A shows the histogram of the circumferential tensile strengths determined for non-coated, EL-SF, and SF-coated SF 


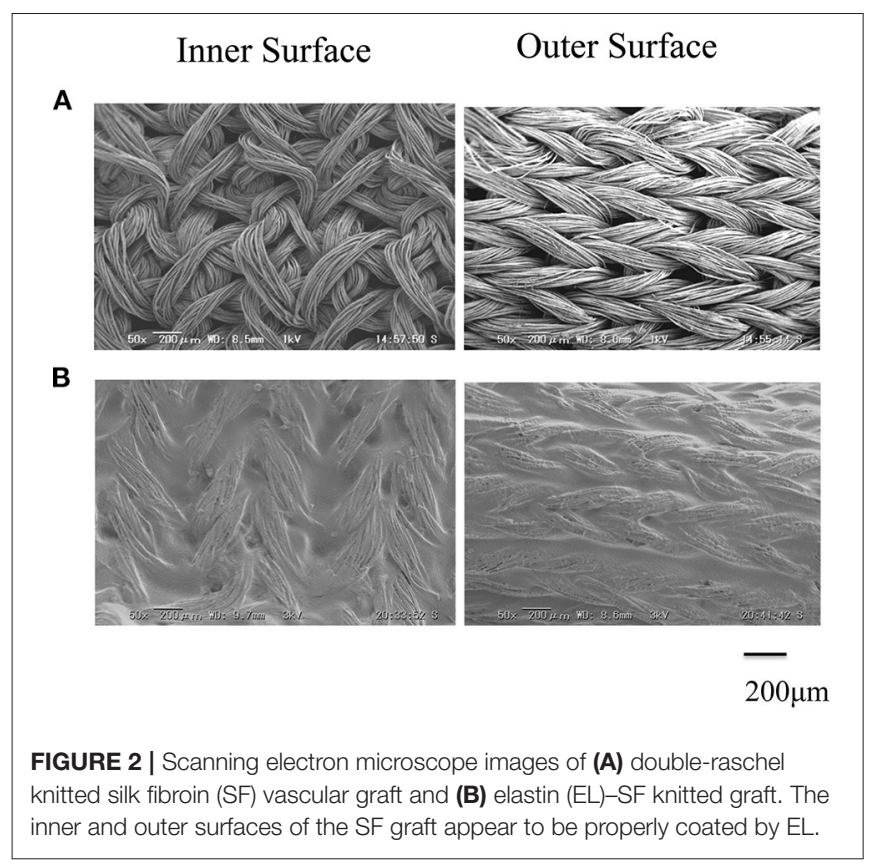

grafts. The tensile strength was increased by coating, and the strength was greater for the EL-SF graft $(38.0 \mathrm{~N})$ than SFcoated SF graft $(34.5 \mathrm{~N})$. On the other hand, the circumferential compressive elastic modulus of the EL-SF graft $\left(0.008 \mathrm{~N} / \mathrm{mm}^{2}\right)$ was lower than the SF-coated SF graft $\left(0.012 \mathrm{~N} / \mathrm{mm}^{2}\right)$, as shown in Figure 4B. Thus, more favorable physical properties were obtained for the SF knitted graft by filling with EL sponge (Asakura et al., 2019).

\section{${ }^{13} \mathrm{C}$ Solid-State NMR Spectra of EL-SF Graft in the Hydrated and Dry States}

Figure 5 shows the (A) ${ }^{13} \mathrm{C}$ r-INEPT, (B) ${ }^{13} \mathrm{C}$ DD/MAS, and (C) ${ }^{13} \mathrm{C}$ CP/MAS NMR spectra of EL-SF grafts in the hydrated state, and (D) shows the ${ }^{13} \mathrm{C} \mathrm{CP/MAS} \mathrm{spectrum} \mathrm{of} \mathrm{the} \mathrm{graft} \mathrm{in}$ the dry state. The expanded region $(0-80 \mathrm{ppm})$ of these spectra are also shown in Figures $6 \mathbf{A}-\mathbf{D}$. The ${ }^{13} \mathrm{C}$ chemical shifts and assignments are listed in Table $\mathbf{1 .}$

The sharp peaks observed in the ${ }^{13} \mathrm{C}$ r-INEPT spectrum, Figure 5A, were assigned to only the ${ }^{13} \mathrm{C}$ nuclei with fast motion in the hydrated EL-SF graft (Tanaka et al., 2018). There are no peaks in the carbonyl region because no ${ }^{1} \mathrm{H}$ nuclei are attached to the carbonyl carbons directly in the ${ }^{13} \mathrm{C}$ r-INEPT spectrum. The ${ }^{13} \mathrm{C}$ r-INEPT spectrum of SF fibers in the hydrated state reported previously (Tanaka et al., 2018) showed sharp random coil peaks of Ala $\mathrm{C} \alpha$, Ala $\mathrm{C} \beta$, Gly $\mathrm{C} \alpha$, Ser $\mathrm{C} \alpha$, and Ser $\mathrm{C} \beta$ carbons. However, these peaks from SF fibers were not seen in the ${ }^{13} \mathrm{C}$ r-INEPT spectra of the EL-SF graft, Figures 5A, 6A. The hydration of the SF chain is suppressed because of the hydrophobic environment around it due to the presence of EL molecules and the crosslinking with EL molecules through the amino groups of the Lys side-chain by glutaraldehyde (Wise et al., 2005). Three peaks, i.e., two Val peaks, $\mathrm{VC}_{\gamma 1}$ and $\mathrm{VC}_{\gamma 2}$, and one Ala $\mathrm{C} \beta$ random coil peak could be observed together with very small Val $\mathrm{C} \beta$, Pro $\mathrm{C} \beta$, Pro $\mathrm{C} \gamma$, Leu $\mathrm{C} \delta_{1}$, and Leu $\mathrm{C} \delta_{2}$ peaks from EL (Figure 6A and Table 1) (Wuethrich, 1976; Asakura et al., 1984; Ohgo et al., 2009; Papaioannou et al., 2015). Two sharp peaks at $63 \mathrm{ppm}$ and $72 \mathrm{ppm}$ are unidentified peaks from impurities.

As shown in Figure 5B, a single large peak at 110.8 ppm was observed from the rotor (Teflon) in the ${ }^{13} \mathrm{C}$ DD/MAS NMR spectrum of the hydrated EL-SF graft. The peak at $129.2 \mathrm{ppm}$ was assigned to aromatic carbons from Tyr ( $\mathrm{C} \gamma$ and $\mathrm{C} \delta$ carbons) and $\mathrm{Phe}(\mathrm{C} \delta, \mathrm{C} \varepsilon$ and $\mathrm{C} \zeta$ carbons) residues (Table 1). The carbonyl peaks were also observed in the range of 171-175 ppm. There are many other peaks in the $10-60 \mathrm{ppm}$ range. These peaks are considered to be due to the carbons in the EL molecules, although the peaks from both EL and SF can be seen. If the peaks from SF were observed in Figure 5B, the Ala C $\beta$ peak from SF should be observed at about 20 ppm (Asakura et al., 1999, 2015b; Holland et al., 2008; Nishimura et al., 2018). However, the Ala $C \beta$ peak could not be seen because of the significantly restricted motion of the SF fibers. The Ala C $\beta$ peak of the SF fibers could

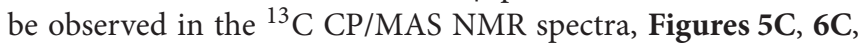
of the hydrated EL-SF graft as the broad peak in the range of 15-25 ppm together with the Gly $\mathrm{C} \alpha$, Ala $\mathrm{C} \alpha$, Ser $\mathrm{C} \alpha$, and Ser C $\beta$ peaks from SF fiber with AP- $\beta$ structure as listed in Table 1 (Asakura et al., 1999, 2015b; Holland et al., 2008; Nishimura et al., 2018). By considering both the amino acid compositions of EL and the ${ }^{13} \mathrm{C}$ chemical shifts of the peaks, the ${ }^{13} \mathrm{C}$ DD/MAS NMR spectrum could be assigned as shown in Figure 6B and listed in Table 1. Thus, the EL molecules in the EL-SF graft are relatively mobile in the hydrated state. As mentioned above, the peaks from the SF fibers were clearly observed in Figures 5C, 6C, and conversely, the peaks from EL became relatively small. This is due to a significant loss in CP signals of the carbons in EL molecules whose mobilities are very high (Yang et al., 2000; Kishore et al., 2002; Holland et al., 2008; Nishimura et al., 2018). The Pro and Leu peaks, in particular, could not be observed in the ${ }^{13} \mathrm{C} \mathrm{CP} / \mathrm{MAS}$ NMR spectrum of the hydrated graft, indicating the high mobility of these residues. The presence of the Pro residues in the primary structure is thought to be a source of higher hydration of the pro-containing protein fibers such as spider silk fiber and elastin fiber (Asakura et al., 2003; Ohgo et al., 2005, 2018; Jenkins et al., 2010; Muiznieks et al., 2015; Dabalos et al., 2019).

Most of the peaks from EL could be seen in the dry state along with the peaks from the SF fibers, as shown in Figures 5D, 6D. The Pro $\mathrm{C} \alpha$, Pro $\mathrm{C} \beta$, and Pro $\mathrm{C} \gamma$ peaks together with Val $\mathrm{C} \alpha$, Val $\mathrm{C} \beta$, and Leu $\mathrm{C} \gamma$ peaks from EL were newly observed (Table 1) (Wuethrich, 1976; Asakura et al., 1984; Ohgo et al., 2005, 2009, 2018; Papaioannou et al., 2015). The peak at 52.8 ppm could be assigned to the $\mathrm{C} \alpha$ peak of Ala residues with the $\alpha$-helical form of EL molecules judging from the chemical shift (Asakura et al., 1999). The presence of the $\alpha$-helical structure of Ala residue has been reported for elastin samples (Papaioannou et al., 2015; Ohgo et al., 2018). Thus, a slightly higher field shift of Ala $C \beta$ peaks compared with the Ala $C \beta$ chemical shifts of the other three NMR spectra (Figures 6A-C) in the hydrated state indicates a mixture of $\alpha$-helix (15.8 ppm) and random coil (16.8 ppm) conformations. The Ala $\mathrm{C} \alpha$ random coil peak (50.3 ppm) 


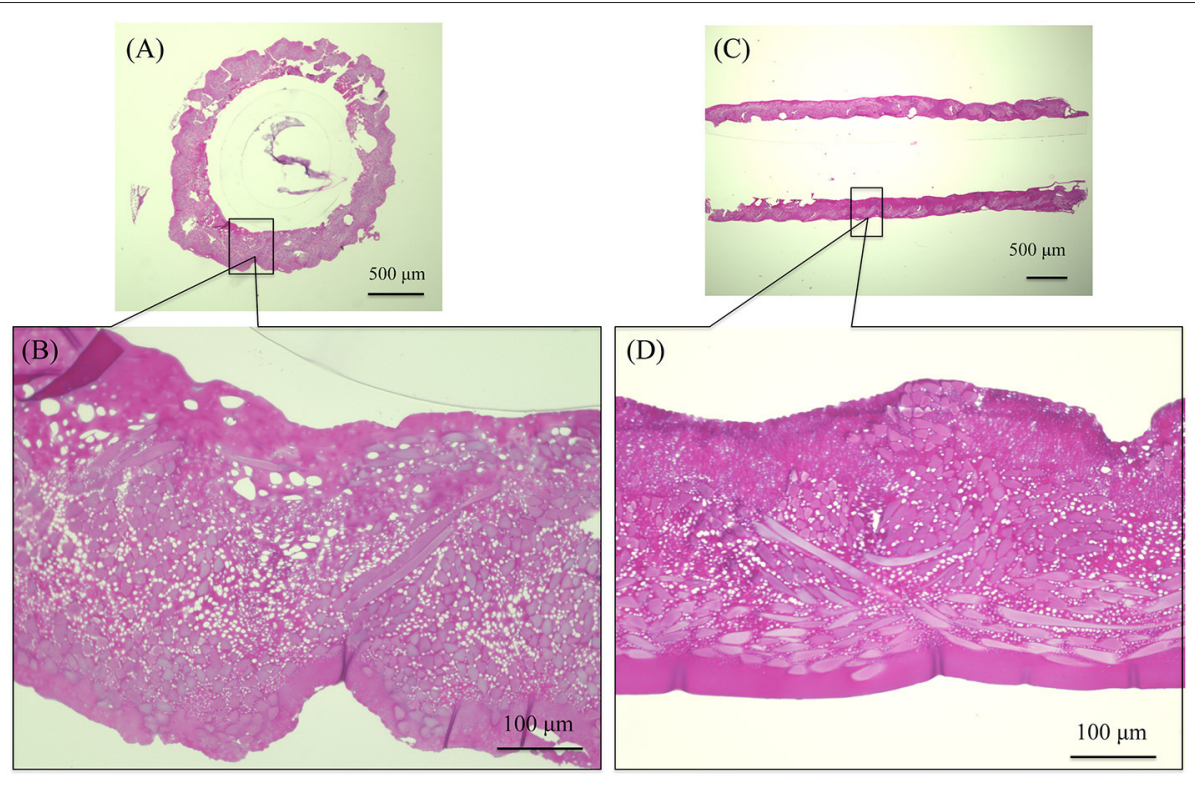

FIGURE 3 | Hematoxylin and eosin staining of elastin (EL)-silk fibroin (SF) graft before implantation: (A) histological cross-section image and (B) higher magnification of the EL-SF graft, (C) histological longitudinal-section image and (D) higher magnification of the EL-SF graft. The gaps among the SF fibers in the double-raschel knitted graft were filled with a lot of spongy EL.
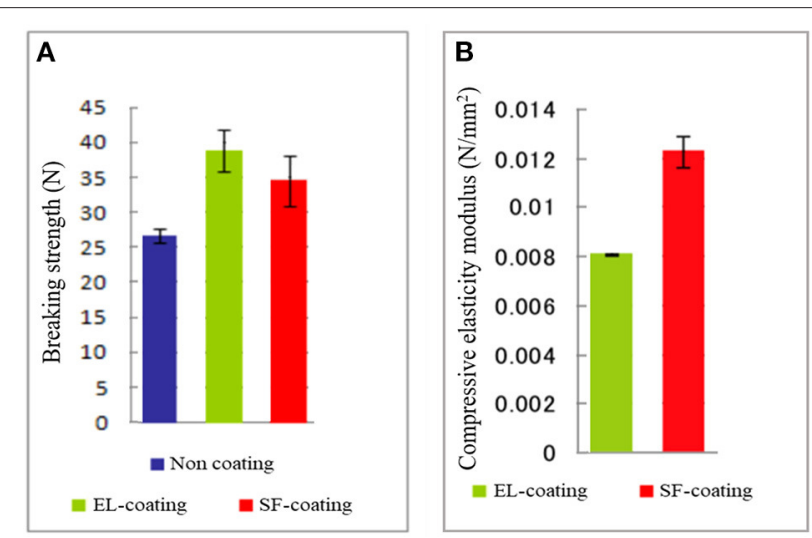

FIGURE 4 | (A) Circumferential tensile strengths determined for non-coated, silk fibroin (SF)-coated and elastin (EL)-coated SF knitted grafts. (B) Circumferential compressive elastic modulus of the EL and SF-coated SF grafts. We could not measure the compressive elastic modulus of non-coated SF graft because it collapsed immediately.

is included in the AP- $\beta$ Ala $\mathrm{C} \alpha$ peak (49.2 ppm). From these NMR data, the high mobility of the EL molecules in the EL-SF graft in the hydrated state became clear, which is expected to be fully functional of EL shown in Figure 1, i.e., minimizing platelet adhesion and promoting endothelial migration.

\section{In vivo Experiment With the EL-SF Graft}

After implanting the EL-SF grafts (Figure 7), all rats were confirmed to have good blood flow. In addition, we confirmed that the tissue was attached sufficiently when all grafts were

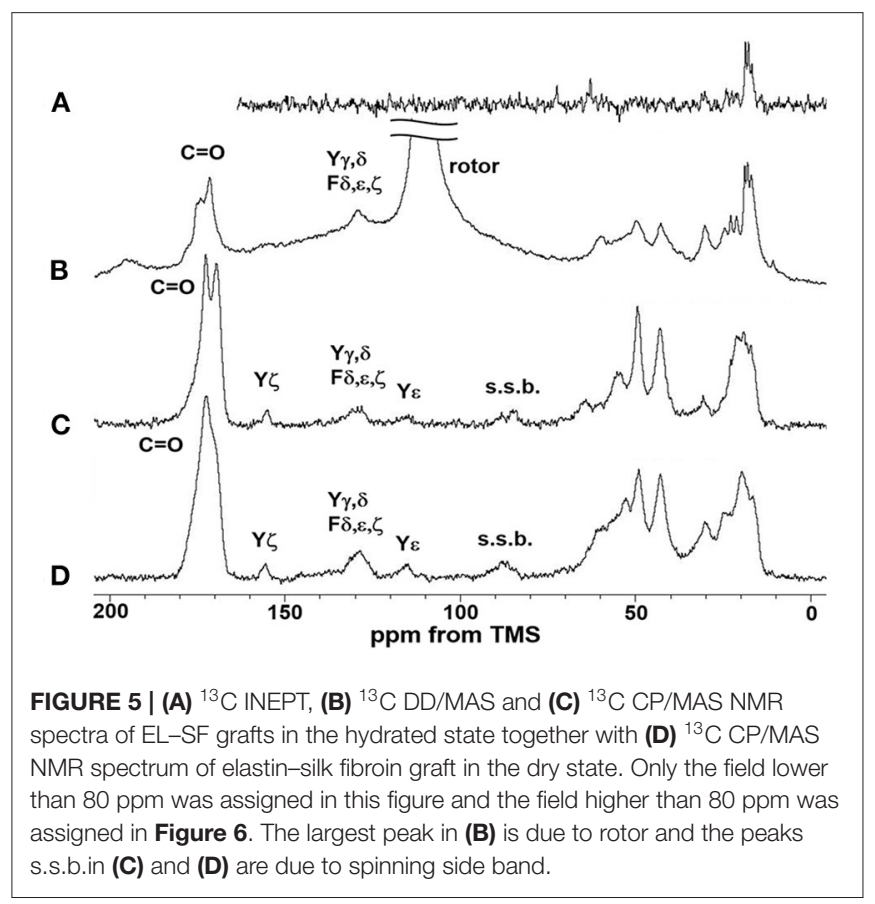

removed. The grafts were mainly covered by fat and infiltrated blood vessels were also observed, Figure 7C. The adipose tissue could be easily detached from the grafts with a cotton swab. The formation of granuloma, which is a foreign body reaction, did not occur. We, therefore, consider that SF and EL used for transplantation were not harmful to rats. 


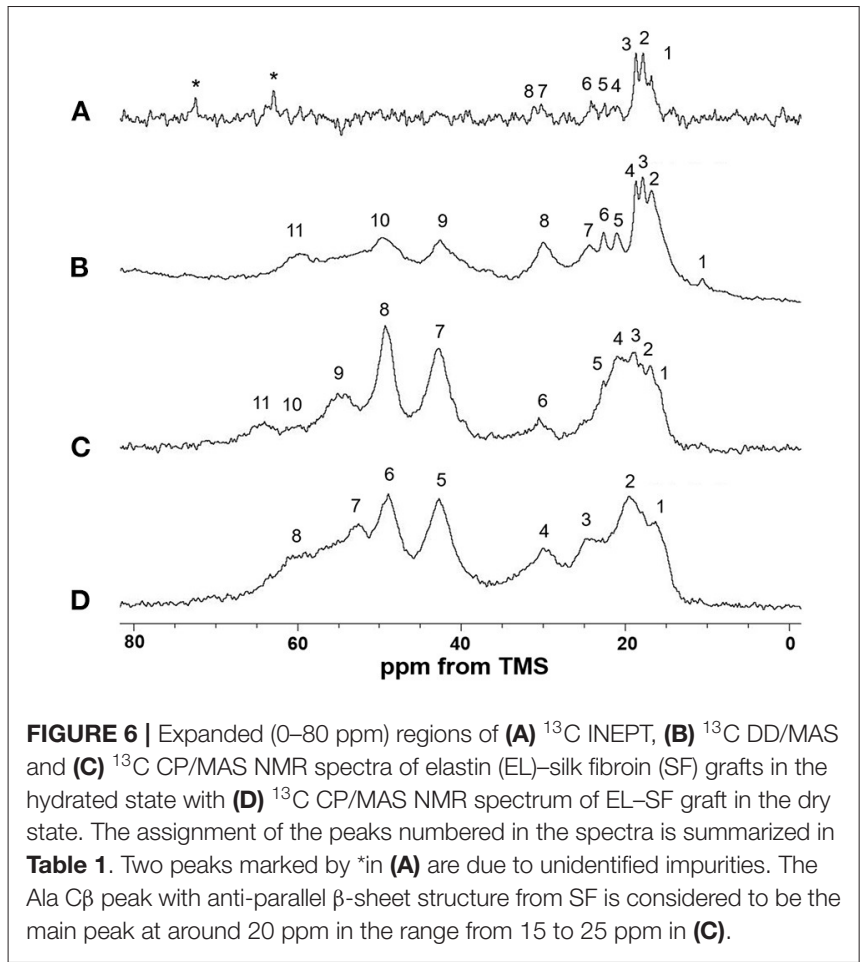

HE staining was used to investigate how the implanted graft changed after implantation. At 2 weeks, there was no cell infiltration into the grafts because the EL sponge had not decomposed (Figure 8A). Since EL molecules filled the gaps between the SF fibers in the grafts, the SF fibers and the filled EL were seen to form a single structure. Inflammatory cells such as neutrophils, lymphocytes, macrophages, and fibroblasts were mainly gathered inside and outside the graft. At 4 weeks after implantation, it was confirmed that the EL was roughly decomposed, and fibroblasts and macrophages invaded the gaps between SF fibers in the graft. The numbers of inflammatory cells accumulated inside and outside the grafts were reduced compared to 2 weeks after implantation, Figure 8B. A layered structure observed in the graft's center was confirmed to have an aggregation of vascular smooth muscle cells and collagen fibers within it. At 12 weeks after implantation, the EL could not be detected, and many fibroblasts and macrophages had invaded the interstices of the SF fibers (Figure 8C). The collagen fibers were dyed blue with MTC staining to examine their involvement in artificial vascular graft remodeling after implantation. The collagen fibers were sparsely present outside and inside the grafts at 2 weeks after implantation (Figure 8D). Since the EL molecules remained inside the graft, the collagen fibers did not initially invade, however, the numbers around the graft increased over time. The collagen fibers also penetrated into the SF fibers (Figure 8E). At 12 weeks after implantation, the number of collagen fibers inside and around the graft increased to cover the entire graft. Further, collagen fibers could be confirmed inside the graft with a concentric, layered formation (Figure 8F). The immunohistochemical staining
TABLE 1 $\mid{ }^{13} \mathrm{C}$ chemical shifts of ${ }^{13} \mathrm{C}$ solid-state NMR spectra of EL-SF graft.

\begin{tabular}{|c|c|c|c|c|}
\hline \multirow{2}{*}{$\begin{array}{l}{ }^{13} \mathrm{C} \text { solid-state } \\
\text { NMR (EL-SF } \\
\text { Graft) }\end{array}$} & \multirow{2}{*}{$\begin{array}{l}\text { Number } \\
\text { (Figure 6) }\end{array}$} & \multirow{2}{*}{$\begin{array}{c}\text { Chemical } \\
\text { shift } \\
\text { (ppm) }\end{array}$} & \multicolumn{2}{|c|}{ Assignment } \\
\hline & & & EL & SF \\
\hline \multirow[t]{8}{*}{ (a)|NEPT(hydrated) } & 1 & 16.8 & $A \beta($ r.c. $)$ & \\
\hline & 2 & 17.9 & $V_{\gamma_{2}}$ & \\
\hline & 3 & 18.7 & $V \gamma_{1}$ & \\
\hline & 4 & 21.2 & $\left\llcorner\delta_{2}\right.$ & \\
\hline & 5 & 22.6 & $\left\llcorner\delta_{1}\right.$ & \\
\hline & 6 & 24.1 & $\mathrm{P} \gamma+\mathrm{L} \gamma$ & \\
\hline & 7 & 30.0 & $P \beta$ & \\
\hline & 8 & 31.1 & $V_{\beta}$ & \\
\hline \multirow{12}{*}{$\begin{array}{l}\text { (b) } \\
\text { DDMAS(hydrated) }\end{array}$} & 1 & 10.7 & $1 \delta$ & \\
\hline & 2 & 16.8 & $A \beta($ r.c. $)$ & \\
\hline & 3 & 17.8 & $V_{\gamma_{2}}$ & \\
\hline & 4 & 18.7 & $V \gamma_{1}$ & \\
\hline & 5 & 21.1 & $\left\llcorner\delta_{2}\right.$ & \\
\hline & 6 & 22.8 & $\left\llcorner\delta_{1}\right.$ & \\
\hline & 7 & 24.4 & $\mathrm{P} \gamma+\mathrm{L} \gamma$ & \\
\hline & 8 & 30.0 & $\mathrm{P} \beta+\mathrm{V} \beta$ & \\
\hline & 9 & 42.8 & $\mathrm{G} \alpha$ & \\
\hline & 10 & 49.4 & $A \alpha($ r.c. $)+P \delta$ & \\
\hline & 11 & 59.4 & $\mathrm{~V} \alpha+\mathrm{P} \alpha$ & \\
\hline & & 129.2 & $Y_{\gamma, \delta}+F \delta, \varepsilon . \zeta$ & \\
\hline \multirow{14}{*}{$\begin{array}{l}\text { (c) } \\
\text { CP/MAS(hydrated) }\end{array}$} & 1 & 16.9 & $A \beta($ r.c. $)$ & \\
\hline & 2 & 18.0 & $V_{\gamma_{2}}$ & \\
\hline & 3 & 19.1 & $V_{\gamma_{1}}$ & $\begin{array}{l}\text { A } \beta(\beta \text {-sheet; } 20 \\
\text { ppm) }\end{array}$ \\
\hline & 4 & 21.1 & $\mathrm{~L}_{2}$ & \\
\hline & 5 & 22.7 & $\mathrm{~L} \delta_{1}$ & \\
\hline & 6 & 30.7 & $V_{\beta}$ & \\
\hline & 7 & 42.6 & $\mathrm{G} \alpha$ & $\mathrm{G} \alpha(\beta$-sheet $)$ \\
\hline & 8 & 49.2 & $A \alpha($ r.c. $+\beta$-sheet $)$ & $\mathrm{A} \alpha(\beta$-sheet $)$ \\
\hline & 9 & 54.4 & & $\mathrm{~S} \alpha(\beta$-sheet $)$ \\
\hline & 10 & 60.3 & $\mathrm{~V} \alpha+\mathrm{P} \alpha$ & \\
\hline & 11 & 64.2 & & $\mathrm{~S} \beta(\beta$-sheet) \\
\hline & & 114.9 & $Y_{\varepsilon}$ & \\
\hline & & 128.6 & $Y_{\gamma}, \delta+F \delta, \varepsilon, \zeta$ & \\
\hline & & 155.0 & $Y_{\zeta}$ & \\
\hline \multirow[t]{11}{*}{ (d) CP/MAS(dried) } & 1 & 16.6 & $A \beta($ r.c. $+\alpha$-helix $)$ & \\
\hline & 2 & 19.3 & & $\begin{array}{l}\text { A } \beta(\beta \text {-sheet; } 20 \\
\text { ppm) }\end{array}$ \\
\hline & 3 & 24.3 & $\mathrm{P} \gamma+\mathrm{L} \gamma$ & \\
\hline & 4 & 29.6 & $\mathrm{P} \beta+\mathrm{V} \beta$ & \\
\hline & 5 & 42.5 & & $\mathrm{G} \alpha(\beta$-sheet $)$ \\
\hline & 6 & 49.2 & $A \alpha($ r.c. $+\beta$-sheet $)$ & $A \alpha(\beta$-sheet $)$ \\
\hline & 7 & 52.8 & $A \alpha(\alpha$-helix) & \\
\hline & 8 & 60.1 & $\mathrm{P} \alpha$ & \\
\hline & & 114.9 & $Y_{\varepsilon}$ & \\
\hline & & 128.7 & $Y_{\gamma}, \delta+F \delta, \varepsilon, \zeta$ & \\
\hline & & 155.2 & $Y_{\zeta}$ & \\
\hline
\end{tabular}

r.c., random coil. 

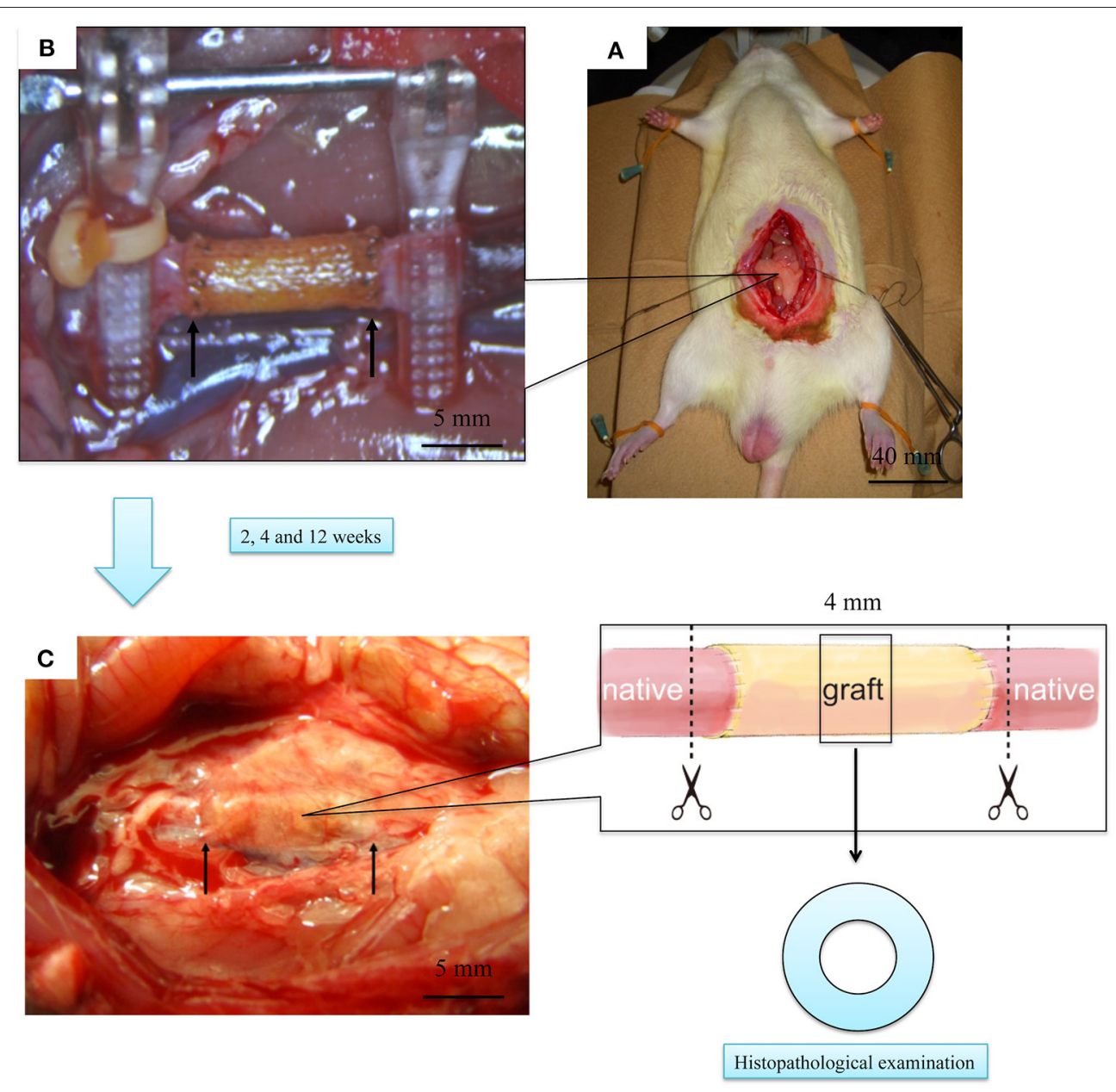

FIGURE 7 | Laparotomy images of the rat implantation experiment of elastin (EL)-silk fibroin (SF) graft. (A) Picture of the graft immediately after transplantation. The two yellow arrows indicate the cranio-caudal anastomosis of the graft. (B) Picture of the rat with open abdomen and transplanted EL-SF graft. (C) Picture of removing artificial vascular graft at 2 weeks after implantation. The grafts, including autologous blood vessels, were removed using scissors at the dotted line.

results confirmed the endothelialization of the central part of the graft as early as 2 weeks. Although it could not be confirmed on part of the luminal surface, most of it adhered to the luminal surface without peeling off from the graft (Figures 9A,B). At 4 weeks after implantation, vascular endothelial cells had completely covered the graft's lumen, which remained unchanged at 12 weeks (Figures 9C-F).

\section{DISCUSSION}

We developed a small-diameter artificial vascular graft using SF (Enomoto et al., 2010; Yagi et al., 2011; Aytemiz et al., 2013; Fukayama et al., 2015a,b; Tanaka et al., 2018, 2020). SF has a long history of biocompatibility having been used as a surgical suture for many years (Altman et al., 2003; Vepari and Kaplan, 2007; Thurber et al., 2015; Tamara et al., 2018). It is known to be biodegradable in vivo, and its shape and properties can be controlled by various processing methods (Horan et al., 2005; Enomoto et al., 2010; Numata et al., 2010; Guo et al., 2020).
Elastin is found in the extracellular matrix of the intima of blood vessels. It accounts for 50\% of the dry weight of arteries, and its properties include endothelial cell compatibility, blood compatibility, and elasticity. It is also attracting attention as an artificial vascular graft combined with other biomaterials (Wilson et al., 2011; Wang et al., 2019). However, because of its highly crosslinked nature, EL is insoluble and difficult to use as a biomaterial (Nivison-Smith et al., 2010).

In this study, we used water-soluble EL prepared from insoluble native elastin by hydrolysis with oxalic acid to improve SF vascular grafts. The beneficial characteristics of EL, i.e., higher attachment of endothelial cells and lower attachment of platelets, were still maintained compared with SF. Thus, we conducted an experiment to develop an EL-SF artificial vascular graft with high biocompatibility to promote endothelialization, antithrombogenicity, and elasticity. Since thrombus formation is the primary cause of occlusion in $<6 \mathrm{~mm}$ diameter grafts (Begovac et al., 2003; Venkatraman et al., 2008; Tatterton et al., 2012), the presence of EL in the graft provided effective 


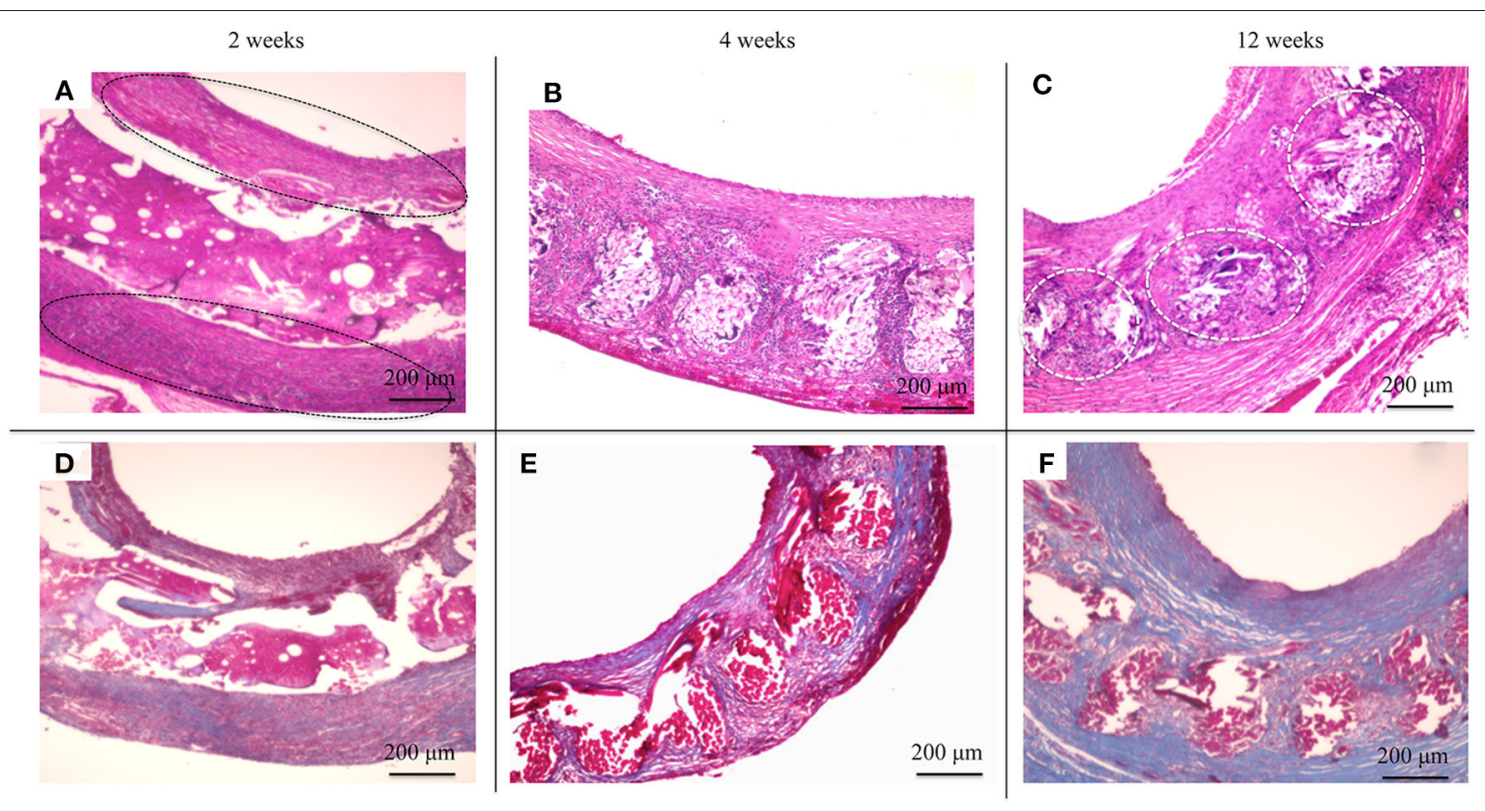

FIGURE 8 | Histological cross-section images at 2 weeks after implantation: (A) hematoxylin and eosin staining (HE) and (D) Masson's trichrome (MTC) staining. Histological cross-section images at 4 weeks after implantation: (B) HE staining and (E) MTC staining. Histological cross-section images at 12 weeks after implantation: (C) HE staining and (F) MTC staining. The black circles indicate the inflammatory cells gathered in layers (A), and the white circles indicate fibroblasts and macrophages had invaded the interstices of the SF fibers (C).
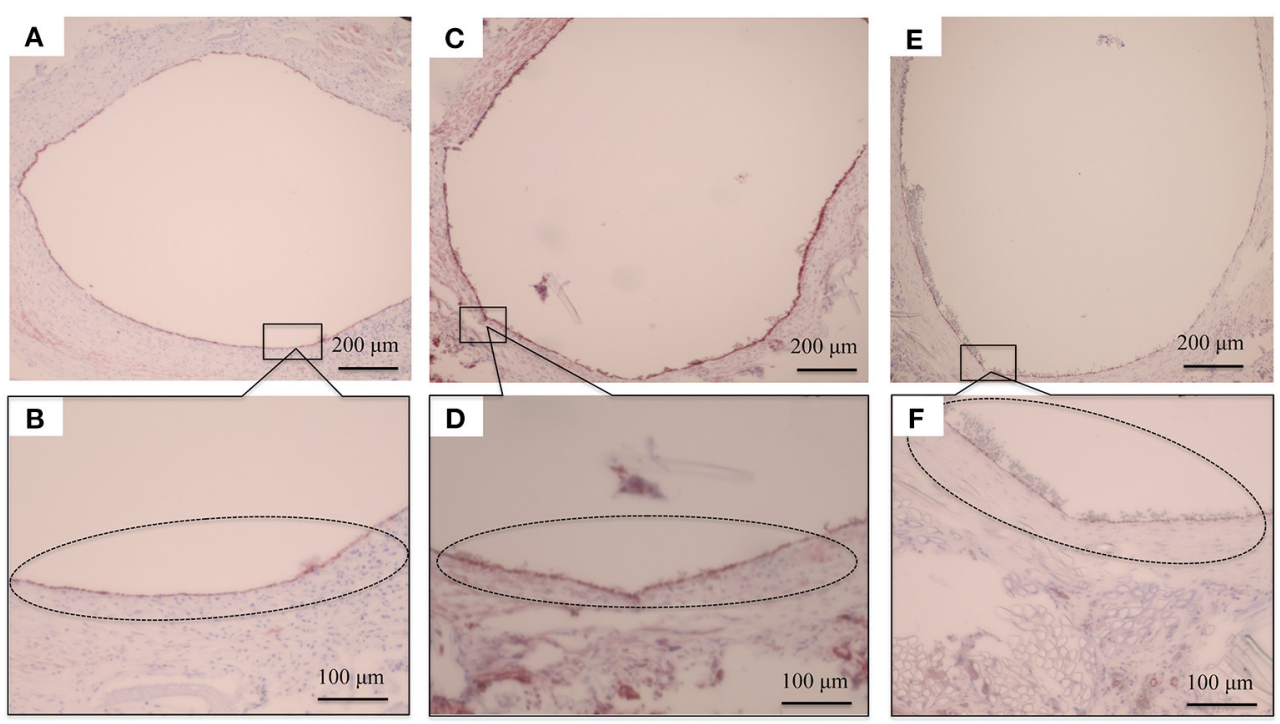

FIGURE 9 | Histopathological photographs of CD31 staining at (A) 2 weeks after implantation and (B) higher magnification. (C) CD31 staining at 4 weeks after implantation and (D) higher magnification. (E) CD31 staining at 12 weeks after implantation (F) and higher magnification. The black circles indicate the vascular endothelial cells adhering to the luminal surface of the graft.

antithrombogenicity. It is also important to prevent leakage of blood during transplant surgery and for the graft to have good physical properties and operability (Salacinski et al., 2001). HE staining of the EL-SF graft showed that spongy EL filled the inner parts, as shown in Figure 3. This prevents blood leakage after implantation and improves the physical properties, including graft operability. We found the blood leakage was mild at the time of implantation. Conventional synthetic polymer materials cause intimal thickening after implantation due to a mismatch in compliance with the autologous blood vessels (Ballyk et al., 1997; Kashyap et al., 2002; Heise et al., 2006); however, the EL-SF graft is expected to solve the compliance difference due to its higher elasticity. We also experienced no loosening due to the needle and anastomosis, indicating improved handling during surgery.

The various ${ }^{13} \mathrm{C}$ solid-state NMR spectra of the EL-SF graft in the dry and hydrated states enabled the characterization of 
the local structure and dynamics of EL and SF molecules at the molecular level. The hydration of the SF chains of the EL-SF graft is suppressed because of the crosslinking with EL molecules and their creation of a hydrophobic environment around the SF chains. On the other hand, the EL molecules in the EL-SF graft are highly mobile in the hydrated state, especially for the Pro and Leu residues. Thus, the EL properties effectively minimize platelet adhesion and promote endothelial migration in the EL-SF graft.

After implantation, patency was confirmed in all EL-SF grafts. No signs such as hematuria, diarrhea, inflammation, tail disintegration, or leg immobility were observed in the rats. The EL molecules on the SF fibers should be antithrombotic, as EL is first exposed to blood when flow resumed (FernándezColino et al., 2019). Since thrombus was not formed, and no occlusion occurred before the EL-SF graft was covered with the vascular endothelial cells, the usefulness of the EL was shown. 2 weeks after the transplantation, many inflammatory cells such as neutrophils and macrophages infiltrated the graft's periphery. However, the accumulation of excessive inflammatory cells and encapsulation by collagen fibers, a type of foreign body reaction, did not occur. It has been reported that inflammation in the transplanted site peaks 7-14 days after the implantation, and decreases as remodeling occurs (Thurber et al., 2015). Since the inflammatory cell numbers decreased at 4 and 12 weeks after the implantation, the implanted EL-SF graft did not cause an abnormal immune response. As shown in Figure 9, the endothelialization of the EL-SF graft occurred rapidly, within 2 weeks of implantation. In addition, the endothelial cells in the lumen became organized without detachment at 4 weeks, suggesting that the EL-SF graft may prevent the blood flow from detaching the endothelial cells. Our results confirm that two factors cause endothelialization in the short term. Firstly, the proliferation and adhesion of endothelial cells starts from the anastomosis and is promoted by EL (Noishiki et al., 1995). Secondly, the endothelial progenitor cells (Asahara et al., 1997) contained in blood migrate to the lumen of the artificial blood vessel due to the decomposition of the EL. Adhesion to the coated surface and organizing by proliferation then occurs. Most of the luminal surface at 2 weeks after implantation was endothelialized, which is earlier than it occurs in SF grafts coated with SF, as demonstrated in earlier studies (Fukayama et al., 2015a,b). Thus, it is likely that dissolved EL was involved after implantation. However, tissue infiltration is unlikely to occur due to the thickness of the coating, and it will be necessary to devise ways to facilitate it. Specifically, a method for thinning the outer coating, which does not reduce the antithrombotic and endothelialization characteristics of EL in the graft's inner coating is needed.

\section{REFERENCES}

Altman, G. H., Diaz, F., Jakuba, C., Calabro, T., Horan, R. L., Chen, J., et al. (2003). Silk-based biomaterials. Biomaterials 24, 401-416. doi: 10.1016/S0142-9612(02)00353-8

Asahara, T., Murohara, T., Sullivan, A., Silver, M., van der Zee, R., Li, T., et al. (1997). Isolation of putative progenitor endothelial cells
The use of a crosslinking agent for glutaraldehyde was not a major problem in this study because it was implanted in rats. For humans, however, it is important to use low-inflammatory elastin (Wise et al., 2011) or a method that does not use a crosslinking agent (Heidenhain et al., 2011; Vasconcelos et al., 2012). In addition, a biopolymer component that has the strength of SF and the elasticity of EL has recently been developed. The researchers performed protein blending on SF with recombinant DNA (Dinjaski and Kaplan, 2016). The fibers obtained with the above technique can be used as the basis for an artificial blood vessel with better physical properties and early remodeling to selforganization. Based on these improvements, long-term artificial vascular graft implantation evaluation in large animals can be carried out, and finally, the development of clinically applicable small-diameter artificial vascular grafts may be achieved.

\section{CONCLUSION}

In this study, we developed an EL-SF $1.5 \mathrm{~mm}$ diameter doubleraschel knitted vascular graft. The SF graft was densely packed with porous EL, which prevented blood leakage from the graft during implantation. The migration of cells after implantation was promoted. The ${ }^{13} \mathrm{C}$ solid-state NMR studies indicated that the EL molecules in the graft have very high mobility in the hydrated state. This graft showed excellent biocompatibility in vitro, and excellent operability and remodeling ability in vivo.

\section{DATA AVAILABILITY STATEMENT}

The raw data supporting the conclusions of this article will be made available by the authors, without undue reservation.

\section{ETHICS STATEMENT}

The animal study was reviewed and approved by Tokyo University of Agriculture and Technology.

\section{AUTHOR CONTRIBUTIONS}

TA and YA designed the study. TT, YA, and AN performed experiment. All authors contributed to the article and approved the submitted version.

\section{FUNDING}

This project has received funding from JSPS KAKENHI, Grantin-Aid for Scientific Research (C), Grant Number JP19K05609 and Grant Number JP20K12643.

for angiogenesis. Science 275, 964-966. doi: 10.1126/science.275.53 02.964

Asakura, T., Aoki, A., Komatsu, K., Ito, C., Suzuki, I., Naito, A., et al. (2020a). Lamellar structure in alanine-glycine copolypeptides studied by solid-state NMR spectroscopy: a model for the crystalline domain of Bombyx mori silk fibroin in silk II form. Biomacromolecules 21, 3102-3111. doi: 10.1021/acs.biomac.0c00486 
Asakura, T., Ashida, J., and Ohgo, K. (2003). Conformational characterization of (Val-Pro-Gly-Val-Gly)6 with ${ }^{13} \mathrm{C}$ solid state NMR. Polym. J. 35, 293-296. doi: 10.1295/polymi.35.293

Asakura, T., Isobe, K., Aoki, A., and Kametani, S. (2015a). Conformation of crystalline and noncrystalline domains of $\left[3-{ }^{13} \mathrm{C}\right]$ Ala-, $\left[3-{ }^{13} \mathrm{C}\right]$ Ser, and $\left[3-{ }^{13} \mathrm{C}\right] \mathrm{Tyr}-$ Bombyx mori silk fibroin in a hydrated state studied with ${ }^{13} \mathrm{C}$ DD/MAS NMR. Macromolecules 48, 8062-8069. doi: 10.1021/acs.macromol.5b02098

Asakura, T., Iwadate, M., Demura, M., and Williamson, M. P. (1999). Structural analysis of silk with ${ }^{13} \mathrm{C}$ NMR chemical shift contour plots. Int. J. Biol. Macromol. 24, 167-171. doi: 10.1016/S0141-8130(98)00082-8

Asakura, T., Ogawa, T., Naito, A., and Williamson, M. P. (2020b). Chain-folded Lamellar structure and dynamics of the crystalline fraction of Bombyx Mori silk fibroin and of (Ala-Gly-Ser-Gly-Ala-Gly) model peptides. Int. J. Biol. Macromol. 164, 3974-3983. doi: 10.1016/j.ijbiomac.2020.08.220

Asakura, T., Okushita, K., and Williamson, M. P. (2015b). Analysis of the structure of Bombyx mori silk fibroin by NMR. Macromolecules 48, 2345-2357. doi: 10.1021/acs.macromol.5b00160

Asakura, T., Suzuki, Y., and Kametani, S. (2018). “Silk," in Encyclopedia of Polymer Science and Technology. John Wiley \& Sons, Inc. doi: 10.1002/0471440264.pst339.pub2

Asakura, T., Tanaka, T., and Tanaka, R. (2019). Advanced silk fibroin biomaterials and application to small-diameter silk vascular grafts. ACS Biomater. Sci. Eng. 5, 5561-5577. doi: 10.1021/acsbiomaterials.8b01482

Asakura, T., Watanabe, Y., Uchida, A., and Minagawa, H. (1984). NMR of silk fibroin.2. ${ }^{13} \mathrm{C}$ NMR study of the chain dynamics and solution structure of Bombyx mori silk fibroin. Macromolecules 17, 1075-1081. doi: $10.1021 / \mathrm{ma} 00135 \mathrm{a} 017$

Aytemiz, D., Sakiyama, W., Suzuki, Y., Nakaizumi, N., Tanaka, R., Ogawa, Y., et al. (2013). Small-diameter silk vascular grafts ( $3 \mathrm{~mm}$ diameter) with a doubleraschel knitted silk tube coated with silk fibroin sponge. Adv. Healthc. Mater. 2, 361-368. doi: 10.1002/adhm.201200227

Baldock, C., Oberhauser, A. F., Ma, L., Lammie, D., Siegler, V., Mithieux, S. M., et al. (2011). Shape of tropoelastin, the highly extensible protein that controls human tissue elasticity. Proc. Natl. Acad. Sci. U.S.A. 108, 4322-4327. doi: $10.1073 /$ pnas. 1014280108

Ballyk, P. D., Walsh, C., Butany, J., and Ojha, M. (1997). Compliance mismatch may promote graft-artery intimal hyperplasia by altering suture-line stresses. J. Biomech. 31, 229-237. doi: 10.1016/S0197-3975(97)00111-5

Begovac, P. C., Thomson, R. C., Fisher, J. L., Hughson, A., and G?llhagen, A. (2003). Improvements in GORE-TEX ${ }^{\circledR}$ vascular graft performance by Carmeda ${ }^{\circledR}$ bioactive surface heparin immobilization. Eur. J. Vasc. Endovasc. Surg. 25, 432-437. doi: 10.1053/ejvs.2002.1909

Budd, J. S., Allen, K. E., Hartley, G., and Bell, P. R. F. (1991). The effect of preformed confluent endothelial cell monolayers on the patency and thrombogenicity of small calibre vascular grafts. Eur. J. Vasc. Surg. 5, 397-405. doi: 10.1016/S0950-821X(05)80171-9

Dabalos, C. L., Ohgo, K., and Kumashiro, K. K. (2019). Detection of labile conformations of elastin's prolines by solid-state nuclear magnetic resonance and fourier transform infrared techniques. Biochemistry 58, 3848-3860. doi: 10.1021 /acs.biochem.9b00414

Dardik, H., Wengerter, K., Qin, F., Pangilinan, A., Silvestri, F., Wolodiger, F., et al. (2002). Comparative decades of experience with glutaraldehyde-tanned human umbilical cord vein graft for lower limb revascularization: an analysis of 1275 cases. J. Vasc. Surg. 35, 64-71. doi: 10.1067/mva.2002.121053

Dinjaski, N., and Kaplan, D. L. (2016). Recombinant protein blends: silk beyond natural design. Curr. Opin. Biotechnol. 39, 1-7.. doi: 10.1016/j.copbio.2015.11.002

Enomoto, S., Sumi, M., Kajimoto, K., Nakazawa, Y., Takahashi, R., Takabayashi, C., et al. (2010). Long-term patency of small-diameter vascular graft made from fibroin, a silk-based biodegradable material. J. Vasc. Surg. 51, 155-164. doi: 10.1016/j.jvs.2009.09.005

Fernández-Colino, A., Frederic, W., Rütten, S., Schmitz-Rode, T., RodríguezCabello, J. C. Stefan J., et al. (2019). Small caliber compliant vascular grafts based on elastin-like recombinamers for in situ tissue engineering. Front. Bioeng. Biotechnol. 7:340. doi: 10.3389/fbioe.2019.00340

$\mathrm{Fu}, \mathrm{C}$., Shao, Z., and Fritz, V. (2009). Animal silks: their structures, properties and artificial production. Chem. Commun. 37, 6515-6529. doi: 10.1039/b911049f
Fukayama, T., Ozai, Y., Shimokawadoko, H., Aytemiz, D., Tanaka, R., Machida, N., et al. (2015a). Effect of fibroin sponge coating on in vivo performance of knitted silk small diameter vascular grafts. Organogenesis 11, 137-151. doi: 10.1080/15476278.2015.1093268

Fukayama, T., Takagi, K., Tanaka, R., Hatakeyama, Y., Aytemiz, D., Suzuki, Y., et al. (2015b). Biological reaction to small-diameter vascular grafts made of silk fibroin implanted in the abdominal aortae of rats. Ann. Vasc. Surg. 29, 341-352. doi: 10.1016/j.avsg.2014.10.008

Guo, C., Li, C., and Kaplan, D. L. (2020). Enzymatic degradation of Bombyx mori silk materials: a review. Biomacromolecules 21, 1678-1686. doi: 10.1021/acs.biomac.0c00090

Heidenhain, C., Veeravoorn, A., Vachkov, B., Weichert, W., Schmidmaier, G., Wildemann, B., et al. (2011). Fibroblast and vascular Endothelial growth factor coating of decellularized vascular grafts stimulates undesired giant cells and graft encapsulation in a rat model. Artif. Organs 35, E1-E10. doi: 10.1111/j.1525-1594.2010.01072.x

Heise, M., Schmidmaier, G., Husmann, I., Heidenhain, C., Schmidt, J., Neuhaus, P., et al. (2006). PEG-hirudin/iloprost coating of small diameter ePTFE grafts effectively prevents pseudointima and intimal hyperplasia development. Eur. J. Vasc. Endovasc. Surg. 32, 418-424. doi: 10.1016/j.ejvs.2006.03.002

Holland, C., Numata, K., Rnjak-Kovacina, J., and Seib, F. P. (2019). The biomedical use of silk: past, present, future. Adv. Healthc. Mater. 8:1800465. doi: $10.1002 / \mathrm{adhm} .201800465$

Holland, G. P., Jenkins, J. E., Creager, M. S., Lewis, R. V., and Yarger, J. L. (2008). Solid-state NMR investigation of major and minor ampullate spider silk in the native and hydrated states. Biomacromolecules 9, 651-657. doi: $10.1021 / \mathrm{bm} 700950 \mathrm{u}$

Horan, R. L., Antle, K., Collette, A. L., Wang, Y., Huang, J., Moreau, J. E., et al. (2005). In vitro degradation of silk fibroin. Biomaterials 26, 3385-3393. doi: 10.1016/j.biomaterials.2004.09.020

Jenkins, J. E., Creager, M. S., Butler, E. B., Lewis, R. V., Yarger, J. L., and Holland, G. P. (2010). Solid-state NMR evidence for elastin-like $\beta$-turn structure in spider dragline silk. Chem. Commun. 46, 6714-6716. doi: 10.1039/c0cc00829j

Kashyap, M. S., Ahn, S. S., Quinones-Baldrich, W. J., Choi, B.-U., Dorey, F., Reil, T. D., et al. (2002). Infrapopliteal-lower extremity revascularization with prosthetic conduit: a 20-year experience. Vasc. Endovascular Surg. 36, 255-262. doi: $10.1177 / 153857440203600402$

Kibbe, M. R., Martinez, J., Popowich, D. A., Kapadia, M. R., Ahanchi, S. S., Aalami, O. O., et al. (2010). Citric acid-based elastomers provide a biocompatible interface for vascular grafts. J. Biomed. Mater. Res. Part A 93A, 314-324. doi: $10.1002 /$ jbm.a.32537

Kishore, A. I., Herberstein, M. E., Craig, C. L., and Separovic, F. (2002). Solid-state NMR relaxation studies of Australian spider silks. Biopolymers 61, 287-297. doi: 10.1002/bip.10150

Koh, L.-D., Cheng, Y., Teng, C.-P., Khin, Y.-W., Loh, X.-J., Tee, S.-Y., et al. (2015). Structures, mechanical properties and applications of silk fibroin materials. Prog. Polym. Sci. 46, 86-110. doi: 10.1016/j.progpolymsci.2015.02.001

Mitchell, S. L., and Niklason, L. E. (2003). Requirements for growing tissue-engineered vascular grafts. Cardiovasc. Pathol. 12, 59-64. doi: 10.1016/S1054-8807(02)00183-7

Miyamoto, K., Atarashi, M., Kadozono, H., Shibata, M., Koyama, Y., Okai, M., et al. (2009). Creation of cross-linked electrospun isotypic-elastin fibers controlled cell-differentiation with new cross-linker. Int. J. Biol. Macromol. 45, 33-41. 4. doi: 10.1016/j.ijbiomac.2009.03.014

Muiznieks, L. D., Reichheld, S. E., Sitarz, E. E., Miao, M., and Keeley, F. W. (2015). Proline-poor hydrophobic domains modulate the assembly and material properties of polymeric elastin. Biopolymers 103, 563-573. doi: 10.1002/bip.22663

Muiznieks, L. D., Weiss, A. S., and Keeley, F. W. (2010). Structural disorder and dynamics of elastin. Biochem. Cell Biol. 88, 239-250. doi: 10.1139/O09-161

Nishimura, A., Matsuda, H., Tasei, Y., and Asakura, T. (2018). Effect of water on the structure and dynamics of regenerated $\left[3-{ }^{13} \mathrm{C}\right]$ Ser, $\left[3-{ }^{13} \mathrm{C}\right]$, and $\left[3-{ }^{13} \mathrm{C}\right]$ Ala-Bombyx mori silk fibroin studied with ${ }^{13} \mathrm{C}$ solid-state nuclear magnetic resonance. Biomacromolecules 19, 563-575. doi: 10.1021/acs.biomac.7b01665

Nivison-Smith, L., Rnjak, J., and Weiss, A. S. (2010). Synthetic human elastin microfibers: stable cross-linked tropoelastin and cell interactive constructs for tissue engineering applications. Acta Biomater. 6, 354-359. doi: $10.1016 /$ j.actbio.2009.08.011 
Noishiki, Y., Yamane, Y., Tomizawa, Y., and Matsumoto, A. (1995). Transplantation of autologous tissue fragments into an e-PTFE graft with long fibrils. Artif. Organs 19, 17-26. doi: 10.1111/j.1525-1594.1995.tb02239.x

Numata, K., Cebe, P., and Kaplan, D. L. (2010). Mechanism of enzymatic degradation of beta-sheet crystals. Biomaterials 31, 2926-2933. doi: 10.1016/j.biomaterials.2009.12.026

Ohgo, K., Ashida, J., Kumashiro, K. K., and Asakura, T. (2005). Structural determination of an elastin-mimetic model peptide, (Val-Pro-Gly-Val-Gly) 6 ,

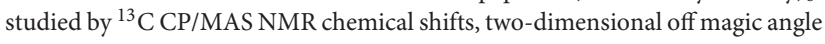
spinning spin-diffusion NMR, rotational echo double resonance, and stati. Macromolecules 38, 6038-6047. doi: 10.1021/ma050052e

Ohgo, K., Dabalos, C. L., and Kumashiro, K. K. (2018). Solid-state NMR spectroscopy and isotopic labeling target abundant dipeptide sequences in elastin's hydrophobic domains. Macromolecules 51, 2145-2156. doi: 10.1021/acs.macromol.7b02616

Ohgo, K., Niemczura, W. P., and Kumashiro, K. K. (2009). Probing the naturalabundance ${ }^{13} \mathrm{C}$ populations of insoluble elastin using ${ }^{13} \mathrm{C}-{ }^{1} \mathrm{H}$ heteronuclear correlation (HETCOR) NMR spectroscopy. Macromolecules 42, 7024-7030. doi: $10.1021 / \mathrm{ma900816k}$

Osborne, J. L., Farmer, R., and Woodhouse, K. A. (2008). Selfassembled elastin-like polypeptide particles. Acta Biomater. 4, 49-57. doi: 10.1016/j.actbio.2007.07.007

Papaioannou, A., Louis, M., Dhital, B., Ho, H. P., Chang, E. J., and Boutis, G. S. (2015). Quantitative comparison of structure and dynamics of elastin following three isolation schemes by ${ }^{13} \mathrm{C}$ solid state NMR and MALDI mass spectrometry. Biochim. Biophys. Acta Proteins Proteomics 1854, 391-401. doi: 10.1016/j.bbapap.2014.12.024

Partridge, S. M., Elsden, D. F., Thomas, J., Dorfman, A., Telser, A., and Ho, P. L. (1964). Biosynthesis of the desmosine and isodesmosine cross-bridges in elastin. Biochem. J. 93, 30C-33C. Available at: http://europepmc.org/abstract/ $\mathrm{MED} / 5839176$

Pereira, R. F. P., Silva, M. M., and de Zea Bermudez, V. (2015). Bombyx mori silk fibers: an outstanding family of materials. Macromol. Mater. Eng. 300, 1171-1198. doi: 10.1002/mame.201400276

Saitô, H., Tuzi, S., Tanio, M., and Naito, A. (2002). Dynamic aspects of membrane proteins and membrane-associated peptides as revealed by 13C NMR: lessons from bacteriorhodopsin as an intact protein. Annu. Rep. NMR Spectrosc. 47, 39-108. doi: 10.1016/S0066-4103(02)47038-X

Salacinski, H. J., Goldner, S., Giudiceandrea, A., Hamilton, G., Seifalian, A. M., Edwards, A., et al. (2001). The Mechanical behavior of vascular grafts: a review. J. Biomater. Appl. 15, 241-278. doi: 10.1106/NA5T-J57A-JTDD-FD04

Saotome, T., Hayashi, H., Tanaka, R., Kinugasa, A., Uesugi, S., Tatematsu, K., et al. (2015). Introduction of VEGF or RGD sequences improves revascularization properties of Bombyx mori silk fibroin produced by transgenic silkworm. J. Mater. Chem. B 3, 7109-7116. doi: 10.1039/C5TB00939A

Takagi, H., Goto, S., Matsui, M., Manabe, H., and Umemoto, T. (2010). A contemporary meta-analysis of Dacron versus polytetrafluoroethylene grafts for femoropopliteal bypass grafting. J. Vasc. Surg. 52, 232-236. doi: 10.1016/j.jvs.2010.02.010

Tamara, A. B., DeSimone, E., and Scheibel, T. (2018). Biomedical applications of recombinant silk-based materials. Adv. Mater. 30:1704636. doi: 10.1002/adma.201704636

Tanaka, T., Tanaka, R., Ogawa, Y., Takagi, Y., and Asakura, T. (2020). Development of small-diameter polyester vascular grafts coated with silk fibroin sponge. Organogenesis 16, 1-13. doi: 10.1080/15476278.2019.1686295

Tanaka, T., Uemura, A., Tanaka, R., Tasei, Y., and Asakura, T. (2018). Comparison of the knitted silk vascular grafts coated with fibroin sponges prepared using glycerin, poly(ethylene glycol diglycidyl ether) and poly(ethylene glycol) as porogens. J. Biomater. Appl. 32, 1239-1252. doi: 10.1177/0885328218 758276

Tatterton, M., Wilshaw, S.-P., Ingham, E., and Homer-Vanniasinkam, S. (2012). The use of antithrombotic therapies in reducing synthetic small-diameter vascular graft thrombosis. Vasc. Endovascular Surg. 46, 212-222. doi: 10.1177/1538574411433299

Thurber, A. E., Omenetto, F. G., and Kaplan, D. L. (2015). In vivo bioresponses to silk proteins. Biomaterials 71, 145-157. doi: 10.1016/j.biomaterials.2015.08.039

Vasconcelos, A., Gomes, A. C., and Cavaco-Paulo, A. (2012). Novel silk fibroin/elastin wound dressings. Acta Biomater. 8, 3049-3060. doi: 10.1016/j.actbio.2012.04.035

Venkatraman, S., Boey, F., and Lao, L. L. (2008). Implanted cardiovascular polymers: natural, synthetic and bio-inspired. Prog. Polym. Sci. 33, 853-874. doi: $10.1016 /$ j.progpolymsci.2008.07.001

Vepari, C., and Kaplan, D. L. (2007). Silk as a biomaterial. Prog. Polym. Sci. 32, 991-1007. doi: 10.1016/j.progpolymsci.2007.05.013

Wang, D., Liu, H., and Fan, Y. (2017). Silk fibroin for vascular regeneration. Microsc. Res. Tech. 80, 280-290. doi: 10.1002/jemt.22532

Wang, R., de Kort, B. J., Smits, A. I. P. M., and Weiss, A. S. (2019). "Elastin in Vascular Grafts," in Tissue-Engineered Vascular Grafts, eds B. Walpoth, H. Bergmeister, G. Bowlin, D. Kong, J. Rotmans, and P. Zilla (Cham: Springer International Publishing), 1-32. doi: 10.1007/978-3-319-71530-8_13-1

Waterhouse, A., Wise, S. G., Ng, M. K. C., and Weiss, A. S. (2011). Elastin as a nonthrombogenic biomaterial. Tissue Eng. Part B Rev. 17, 93-99. doi: 10.1089/ten.teb.2010.0432

Wilson, B., Gibson, C., Sorensen, L., Guilhermier, M., Clinger, M., Kelley, L., et al. (2011). Novel approach for endothelializing vascular devices: uderstanding and exploiting elastin-endothelial interactions. Ann. Biomed. Eng. 39, 337-346. doi: 10.1007/s10439-010-0142-z

Wise, S. G., Byrom, M. J., Waterhouse, A., Bannon, P. G., Ng, M. K. C., and Weiss, A. S. (2011). A multilayered synthetic human elastin/polycaprolactone hybrid vascular graft with tailored mechanical properties. Acta Biomater. 7, 295-303. doi: 10.1016/j.actbio.2010.07.022

Wise, S. G., Mithieux, S. M., Raftery, M. J., and Weiss, A. S. (2005). Specificity in the coacervation of tropoelastin: solvent exposed lysines. J. Struct. Biol. 149, 273-281. doi: 10.1016/j.jsb.2004.11.006

Wise, S. G., Mithieux, S. M., and Weiss, A. S. (2009). "Engineered tropoelastin and elastin-based biomaterials," in Advances in Protein Chemistry and Structural Biology Advances in Protein Chemistry and Structural Biology, ed A. McPherson (San Diego, CA; Academic Press), 1-24. doi: 10.1016/S1876-1623(08)78001-5

Wuethrich, K. (1976). NMR in biological research: peptides and proteins. Amsterdam: North Holland Pub. Available at: https://agris.fao.org/agrissearch/search.do? recordID=XF2015021912

Yagi, T., Sato, M., Nakazawa, Y., Tanaka, K., Sata, M., Itoh, K., et al. (2011). Preparation of double-raschel knitted silk vascular grafts and evaluation of short-term function in a rat abdominal aorta. J. Artif. Organs 14, 89-99. doi: 10.1007/s10047-011-0554-z

Yang, Z., Liivak, O., Seidel, A., LaVerde, G., B., Zax, D., et al. (2000). Supercontraction and backbone dynamics in spider silk: $13 \mathrm{C}$ and $2 \mathrm{H} \mathrm{NMR}$ studies. J. Am. Chem. Soc. 122, 9019-9025. doi: 10.1021/JA0017099

Yokota, T., Ichikawa, H., Matsumiya, G., Kuratani, T., Sakaguchi, T., Iwai, S., et al. (2008). In situ tissue regeneration using a novel tissue-engineered, small-caliber vascular graft without cell seeding. J. Thorac. Cardiovasc. Surg. 136, 900-907. doi: $10.1016 /$ j.jtcvs.2008.02.058

Conflict of Interest: The authors declare that the research was conducted in the absence of any commercial or financial relationships that could be construed as a potential conflict of interest.

Copyright (c) 2021 Tanaka, Abe, Cheng, Tanaka, Naito and Asakura. This is an open-access article distributed under the terms of the Creative Commons Attribution License (CC BY). The use, distribution or reproduction in other forums is permitted, provided the original author(s) and the copyright owner(s) are credited and that the original publication in this journal is cited, in accordance with accepted academic practice. No use, distribution or reproduction is permitted which does not comply with these terms. 